\title{
Research on the Effectiveness of China's A-share Main Board Market
}

\author{
Yekai LI ${ }^{1}$ \\ ${ }^{1}$ South University of science and technology, Mianyang, Sichuan
}

\begin{abstract}
The effectiveness of the stock market is an important indicator to measure the efficiency of capital allocation in the secondary financial market, and is of great significance to the operation of the national economy. Whether the Mainland China's stock market is weakly effective has always been controversial. This article uses the measurement method to conduct empirical data research on the five randomly selected stocks and the Shanghai Composite Index, analyzes the conclusions and analyzes the underlying reasons that lead to the low effectiveness of the Mainland China stock market.
\end{abstract}

\section{Introduction}

\subsection{Research background}

In 1965, Eugene Fama, a professor of finance at the University of Chicago in the United States, published a paper entitled "Stock Market Price Behavior" and proposed an efficient market hypothesis. In 1952, Markowitz published an article on "asset selection", and the study of economics entered a new era, realizing a leap from qualitative to quantitative.

In 1990, the Chinese government allowed Shanghai and Shenzhen to pilot public offerings of stocks, but they did not receive much attention. In 1995, China once again took measures to focus on supporting the stock market, creating a relaxed political environment for the development of the stock market, and the stock market also used this to help rapid development. Therefore, China's research on stock market efficiency began mainly in 1995.

\subsection{Research significance}

First, exploring whether the Chinese stock market is weakly effective. At present, the United States still has the largest stock market in the world, with a total volume of approximately US \$ 31 trillion. In 2015, China's stock market once surpassed US \$ 10 trillion. However in 2018, China gave way to the title of the world's second largest stock market in Japan, at which time the market value of the Chinese stock market shrank to about 6 trillion US dollars. Most of the 828 new shares added during the three years have plummeted, and the worst of them is the ChiNext, which has broken a three-year low. This means that even after nearly 30 years of development, China's stock market is still chaotic, such as dealer trading, listed company circling, and large shareholder misappropriation of funds. Measuring and evaluating the effectiveness of China's domestic stock market and its influencing factors can provide references for investors and investment institutions, and provide help for further improving the effectiveness of our domestic stock market.

Second, exploring whether the CAPM model is applicable to the Chinese stock market. The CAPM model has proven its applicability in mature financial markets, but its applicability in the Chinese market remains controversial. Whether the CAPM model is applicable is actually an important reflection of the maturity of the financial market. After years of financial market reforms, China's financial market governance has improved, but China should take advantage of the chase to further improve the market mechanism, create a fair and just investment environment for investors, and optimize the rational allocation of social resources.

\section{Literature review}

First of all, some scholars believe that the Chinese stock market has not yet reached the weak form, mainly based on the six methods of CAPM model, genetic programming technology, BDS test, comparative analysis of comprehensive stock indexes with stock markets around the world, R / S analysis method, and variance ratio test method. Jin Yunhui and others also used the CAPM basic model to measure the data from 1997 to 2000, and reached the same conclusion. Xie Baohua et al. studied the Shanghai Composite Index from December 21, 2001 to March 2002 and the Shenzhen Component Index from December 1, 1995 to March 2002, with a total of 772 weekly closing prices, and believed that the weak form of the Chinese securities market was not valid. $\mathrm{Hu}$ Changsheng and others measured the Shanghai Composite Index and Shenzhen Composite Index from 1992.5.21 to 2003.20, and believed that the Shanghai and Shenzhen 
stock markets do not yet have weak-form effectiveness, but the effectiveness is indeed improving. Gu Rongbao and others believe that although the Chinese stock market has not yet reached weak-form effectiveness, the 2005 split share structure reform will play a considerable role in promoting the effectiveness of the stock market in the long run. Li Linxiang divided the data into three phases: 1990.12.20-1996.10.16 for the early market, 1996.10.17-2007.10.17 for the bull market, and 2007.10.18-2013.11.20 for the bear market. The Shanghai Composite Index closed for a total of 5605 trading days The price is a sample, and the analysis shows that the market efficiency may be gradually rising. The bear market is more effective than the bull market, and the bull market is more effective than the early stage; however, it is also believed that even if the efficiency is gradually rising, the Chinese stock market has not yet reached weakform efficiency. Yan Luo et al. 1992.1-2013.12 Shanghai and Shenzhen A-share daily and monthly yield data researched the stock miscalculation based on stock price deviation from the predicted intrinsic value, and believed that the stock misvaluation in the Chinese A-share market has a strong The ability to predict earnings may be due to the low efficiency of the Chinese market. However, it also pointed out that after 2005, the misvaluation effect of China's stock market has weakened, affirming the positive effect of the shareholding reform on the efficiency of China's stock market. Wang Weihan's analysis of Shanghai stock market data (2011.1.1-2016.1.1) believes that the impact of non-systemic risk on the return rate is greater than systemic risk, so the weak form is not valid. Qu Hui et al. used a technical trading system based on genetic programming to measure the historical data of the Shenzhen 100 Index for a total of 1503 trading days from 2004.01.02 to 2010.03.12, and believed that the Chinese stock market has not yet reached weak-form efficiency. Wang Hongxia et al. used genetic programming to measure the Shanghai Composite Index and 5 stocks in the Shanghai and Shenzhen stock markets. The results suggest that China's stock market has not reached weak-form efficiency. Wei Sun studied the composite indexes of SHA, SHB, SZA, SZB, and non-inland HKCEI from 1998 to 2012 and the stock markets of various countries in the world. The study found that the correlation between the mainland China stock market and other stock markets in the world is not significant, while Hong Kong The stock market is closely connected with other stock markets in the world, that is, China's inland stock market has not reached weak-form efficiency. Tan Xueyan used the R / S analysis method to divide the Chinese stock market into four stages: the budding stage, the preliminary formation stage, the rapid development stage, and the further standardization stage. Compared, there is no obvious approach to efficient markets. Ran Maosheng also analyzed the 10 large-cap stocks in the Shanghai stock market from 1995.1.1 to 2005.12.31 using the R / S method, and also believed that the effectiveness of the Chinese stock market was not established. Li Jia et al. tested the Shanghai and Shenzhen 300 indexes from 2005.4.8 - 2007.11.29 and 1999.11.26-2007.11.29 using the method of variance comparison test. They believe that China's stock market is effective in the short term, while the medium and long term is basically invalid because of strong government Intervened in the operation of the stock market.

In addition, some scholars believe that the Chinese mainland stock market has initially been weakly effective. They mainly use time series analysis, difference significance analysis and five-factor model.

Deng Zilai et al. tested the stock prices of 20 companies listed on the Shanghai and Shenzhen stock markets from 1998.7-1998.8 through weak-form random travel, and tested 12 stocks listed on the Shenzhen and Shanghai stock markets from 1997.6.1 to 1997.12.1 through weak-form autoregression. The stock index of the stock market and stock market, the research believes that after two years of development, China's two stock markets have initially been weakly effective. Ma Yanxiang analyzed the historical data on the return rates of Shenzhen and Shanghai stock markets from 2007 to 2008 and pointed out that neither the Shenzhen and Shanghai markets have autocorrelation or partial autocorrelation, which meets the requirements of weakly efficient market inspection, so they are all weakly efficient markets. Zhu Konglai et al. used the daily closing price and daily rate of return of the Shanghai and Shenzhen stock market composite indices from 2010.1.4 to 2011.4.1. The study believes that the Shanghai and Shenzhen markets have basically achieved weak-form effectiveness, and the Shanghai Composite Index is against the Shenzhen Composite Index. The daily rate of return has a certain predictive effect, and the Shanghai and Shenzhen stock markets have basically reached a combined weak form.

Zeng Jinsong adopted a two-stage test method to test the data from 1998 to 2004, and the results showed that the technical analysis method did indeed obtain less returns in the latter period than in the previous period, and the effectiveness of the market was enhanced. Zhou Luo et al. improved the CAPM model, taking the scale factor, book-to-market ratio factor, profitability factor, and investment model factor into the model, and found that the degree of fitting was significantly better (up to $65 \%$ fitting rate), but The explanation effect is still not as good as the US market.

\section{Model selection and experimental steps}

\subsection{Brief description of the model}

\subsubsection{Proposed model}

The CAPM model was first proposed by Markowitz, and then developed and improved by economists such as Sharp (W. Sharpe), Lintner (J. Lintner) and Mossin (J. Mossin). The CAPM model contains Six assumptions: first, the market is completely competitive; second, investors have the same investment period and do not consider the situation after the investment expires; third, investors can freely obtain risk-free interest rates; fourth, market circulation is completely free There is no transaction cost and information asymmetry; Fifth, the 
rational person hypothesis; Sixth, the investor expects a consistent hypothesis.

\subsubsection{Mathematical expression of the model}

$$
E\left(R_{i}\right)=R_{F}+\left[E\left(R_{M}\right)-R_{F}\right] \frac{\operatorname{COV}\left(R_{i}, R_{M}\right)}{\sigma_{M}^{2}}=R_{F}+\beta_{i M}\left[E\left(R_{M}\right)-R_{F}\right]
$$

The meaning of this formula is: expected return of a single stock $=$ risk-free return + risk degree $*$ market excess return (risk return) rate.

\subsection{Data sources and selection}

\subsubsection{Market mix}

Select the Shanghai Composite Index (000001.SH) as the market combination. Compared with the Shenzhen Component Index, the SSE Composite Index covers a wider range (including all stocks listed on the Shanghai Stock Exchange), has been stable and has a long history.

\subsubsection{Single stock}

Five stocks were randomly selected as the object of this study, including: 603988.SH, 000839.SZ, 601066.SH, 002157.SZ, 300688.SZ.

\subsubsection{Risk-free interest rate}

Taking China's one-year government bond interest rate of $2.6 \%$ as the risk-free interest rate, equivalent to weekly interest rate returns, it is about $0.049863 \%$.

\subsubsection{Rate of return calculation}

Yield is equal to the change in the closing price of a week from the previous week. If the closing price becomes higher, the yield is positive; otherwise, it is negative. All yields must be processed before ex-rights and exdividends.

\subsubsection{Time span}

This article selects the Shanghai Composite Index from January 9, 2015 to December 31, 2019 and the weekly closing prices of five stocks (a total of 200 weeks) as experimental data. Most of the research results show that the Chinese stock market before 2015 is not effective, but some new research results show that the Chinese stock market after 2015 has gradually moved to a weak and effective stage, so this paper chooses such a 2015-2019 Time to verify whether the Chinese stock market has initially possessed weak and effective characteristics. In addition, the Chinese stock market has a strong cyclicality. The Chinese stock market is in a relatively stable cycle after 2015, which is conducive to improving the accuracy of the experimental results in this article.

\subsection{Experimental steps and results}

\subsubsection{Regression estimates the coefficient of a single stock (systemic risk degree)}

$$
R_{i t}=\alpha+\beta_{i M} \cdot R_{M t}+\varepsilon_{t}
$$

$R_{i t}$ and $R_{M t}$ are processed by the ex-rights and exdividends from the sample data, and a simple calculation of the weekly rate of return is available. $\alpha$ and $\beta_{i M}$ are parameters to be estimated, ${ }^{\varepsilon_{t}}$ is random interference, $E\left(\varepsilon_{t}\right)$ is 0 . Through this measurement model, regression analysis was performed on the five stocks, and the corresponding stocks were obtained.

Table1. Single stock regression results

\begin{tabular}{|l|l|l|l|l|l|}
\hline & $603988 . \mathrm{SH}$ & $000839 . \mathrm{SZ}$ & $601066 . \mathrm{SH}$ & $002157 . \mathrm{SZ}$ & $300688 . \mathrm{SZ}$ \\
\hline$\alpha$ & -0.000822 & -0.012443 & 0.002347 & 0.011341 & 0.002447 \\
\hline$\beta_{i M}$ & 0.544142 & 1.112938 & 1.123557 & 1.222342 & 1.303434 \\
\hline$\overline{R^{2}}$ & 0.253212 & 0.334991 & 0.234568 & 0.586928 & 0.404544 \\
\hline $\begin{array}{l}\mathrm{F} \\
\text { Statistics }\end{array}$ & 73.313453 & 119.82351 & 267.1356 & 121.3253 & 141.9334 \\
\hline
\end{tabular}

First, the meaning of the intercept term $\alpha$. If the intercept term is equal to 0 , it means that the expected return of the stock matches the actual return. The two are consistent, and the value and price are balanced. The stock price will be predicted to be stable; if the intercept term is greater than 0 , it means that the stock is expected to be higher than the actual return., That is, the market is overheated and the price is high, rational people should reduce their holdings; if the intercept term is less than 0 , it means that the expected return of the stock is lower than the actual return, that is, the market is underreacted, the price is low, and the stock digital price is lower than its market price. The real potential of value, the market underestimated the stock, rational people should take this opportunity to increase their holdings. It can be seen from the above data that the stock prices of 603988.SH and 000839.SZ are relatively low, while those of 601066.SH, 002157.SZ and 300688.SZ are relatively high.

Second, the meaning of the coefficient of determination. The coefficient of determination is an index used to measure the fit of the regression equation to the original data. If the coefficient of determination is greater than 0.5 , the return of individual stocks will be greatly affected by the market; if the coefficient of determination is less than 0.5 , the income of individual stocks will be mainly affected by the fundamentals of the company, but not by the market. It can be seen from the above data that 601066 .SH is greatly affected by the market, and the returns of 002157.SZ, 300688.SZ, 000839.SZ and 603988.SH are sequentially weakened by the market, but affected by the company's fundamentals. The intensity increases in turn. 


\subsubsection{Regression analysis of the average value and coefficient of each stock's rate of return}

$$
E\left(R_{i}\right)=R_{F}+E\left(\beta_{i M}\right) \cdot E\left(R_{M}\right)+\varepsilon_{i}
$$

$E\left(R_{i}\right)$ and $E\left(R_{M}\right)$ can be obtained by averaging the weekly returns of the sample data. $R_{F}$ and $E\left(\beta_{i M}\right)$ is the parameter to be estimated, $\varepsilon_{t}$ is random interference, $E\left(\varepsilon_{t}\right)$ is 0 . Get the corresponding $R_{F}$ and $E\left(\beta_{i M}\right)$ through this measurement model.

Table2. Single stock re-regression results

\begin{tabular}{|c|c|c|}
\hline & $R_{F}$ & $E\left(\beta_{i M}\right)$ \\
\hline $603988 . \mathrm{SH}$ & -0.001252 & 0.512443 \\
\hline $000839 . \mathrm{SZ}$ & -0.010300 & 1.132123 \\
\hline $601066 . \mathrm{SH}$ & 0.012407 & 1.351247 \\
\hline $002157 . \mathrm{SZ}$ & 0.002449 & 1.213568 \\
\hline 300688.SZ & 0.001297 & 1.124554 \\
\hline $\begin{array}{c}\text { Shanghai Composite } \\
\text { Index }\end{array}$ & -0.000928 & 1.01 \\
\hline
\end{tabular}

\subsubsection{Empirical analysis results}

According to the basic principles of the CAPM model, three points need to be verified:

First, whether there is a positive correlation between assets and earnings. There is a positive correlation between assets and income, which can also be expressed as a stock's risk spillover income is positive, that is $E\left(\beta_{i M}\right)>0$. According to the regression results, the correlation coefficient 0.004112 is indeed greater than zero.

Second, is the risk-free rate of return equal to the set risk-free rate of return? Is the risk-free rate of return equal to the model setting, ie $E\left(R_{0 t}\right)=R_{F}$. China's one-year Treasury weekly interest rate is $0.04143 \%$, which is not equal to the calculated value $-0.4002 \%$. This article does not hold.

Third, whether the regression results of constant terms and correlation coefficients pass the significance test. If both test results are significant at the same time, then CAPM is considered effective in the Chinese stock market; if the constant term test is not significant, but the correlation coefficient test is significant, the market excess return and individual stock excess return are linearly related, but the CAPM model cannot be completely Explain the problem of return on individual stocks in the Chinese market; if the test result of the constant term is significant, but the test result of the correlation coefficient is not significant, it is considered that there is no correlation between the market excess return and the individual stock excess return. CAPM cannot effectively explain the The return of individual stocks; if the results of the two tests are not significant, it is also considered that there is no linear correlation between the excess return of the market and the excess return of individual stocks, and CAPM cannot effectively explain the return of individual stocks in the Chinese stock market. Use the test method of econometrics:

The constant term (estimated risk-free rate of return $R_{F}$ ) is -0.003822 and the t-test statistic is -1.132184 . The correlation coefficient (estimated risk premium $E\left(\beta_{i M}\right)$ ) is 0.004112 , and the t-test statistic is 0.002873 . Because the t-test statistic of the constant term and correlation coefficient is significantly smaller than the critical value, it is considered to be consistent with the fourth result-there is no linear correlation between the market excess return and the individual stock excess return. The issue of individual stock returns.

\section{Realistic analysis of the low effectiveness of the Chinese stock market}

According to the data analysis results, there is no linear correlation between market excess returns and individual stock excess returns. CAPM cannot effectively explain the issue of individual stock returns in the Chinese stock market. This reflects that there are many non-economic factors in the economic stock market that affect the stock market's rate of return.

\subsection{The stock market is greatly affected by macro-control}

The role of government in the economy is very complex. Keynesianism believes that the government should act as a referee and regulator to regulate the economy. However, in the regulation, there will inevitably be a lot of excessive regulation, which has led to

In a normal economic market, the return on stocks and many macro factors have a clear correlation, industrial added value and retail sales of social consumer goods are positively affecting stock market volatility, and this effect changes with time or economic environment Changes. But when the government excessively intervenes in these areas, it will lead to market failure, which will lead to a disconnect between the stock market and the macro economy. From 2002 to 2005, China's economic growth has been very strong, but at the same time, the Chinese stock market has continued to decline for four years.

The central bank regulates the money supply, thereby acting on interest rates and affecting stock prices. Specifically, if the central bank adopts a loose monetary policy to loosen money, the money supply in the market will increase, making the funds more loose. Once the market interest rate is reduced, the yield of bonds and bank deposits will be reduced, while stocks The income of the company has risen relatively, and the stock has become an ideal investment target, and a large amount of capital has poured into the stock market to push the stock price up. Conversely, if the bank adopts a tight monetary policy and 
reduces the money supply, the money supply in the market will be reduced, and the funds will be tight. This is because the market interest rate will be raised accordingly, and the income of bonds and bank deposits will be relatively increased. Investors are more inclined to invest in fixedincome products. When the funds leave the stock market and the transaction shrinks, the stock price will fall. The government's supply of money will greatly affect the stock market's yield, resulting in the stock price's reaction to market changes not being obvious.

The country has three strategies for holding shares. One is to control $100 \%$ of the company's shares, the other is to control more than $50 \%$ of the company's shares, and the third is to control less than $50 \%$ of the shares, but the state is the largest shareholder. This kind of policy has certain advantages and will also bring disadvantages to the development of the market economy. First of all, stateowned enterprises stimulate employees' enthusiasm and creativity by giving employees the right to participate in the distribution of residual profits of the enterprise, but because of state control, the company's internal employees hold shares Rarely, the limited quota of employees' participation in the distribution of remaining assets is difficult to inspire employees' enthusiasm for labor. And the ban on the circulation of state-owned shares in the secondary market restricts the development of the secondary market. At the same time, the share prices of state-owned enterprises are mostly affected by market fluctuations. Very small.

\subsection{Inappropriate companies after IPO \\ governance of listed}

There are problems with the application of funds raised on the GEM. According to Liu Tingna's statement, based on 627 companies, the direction of large amounts of cash investment is not clear. Only $36.56 \%$ of the funds raised are used for investment related to the company's main business, but there are bank Funds accounted for 17.76\%. The flow of over-raised funds was mainly composed of six major blocks: main business investment, repayment of bank loans, supplementary working capital, deposit of bank interest, housing purchases and capital replacement. Among them, part of the funds for replenishing working capital and repaying bank loans entered the bank again through various forms of turnover. It can be said that the over-raised funds did not really play a role.

The original shareholder cashed in a high position. From January 2003 to the end of 2014, according to incomplete statistics, a total of 10 executives of listed companies fled, and the black holes that were taken away or caused by the funds amounted to nearly 10 billion. Company executives misappropriated funds and escaped Slowing down or even seriously causing the company's capital flow will lead to the break of the capital chain. The frequent occurrence of such events will cause the stock price of a normally operating company to suddenly fall, which does not conform to the laws of the normal economic market.

The problem of financial fraud is outstanding. In 2003, Wanfushengke was established. The company went public in October 2009. In September 2012, the Hunan Securities Regulatory Bureau of the China Securities Regulatory Commission conducted an investigation on Wanfushengke. After October, Wanfushengke admitted that Half-year financial data was falsified, falsely reported operating income of 188 million yuan, falsely increased cost of 146 million yuan, and falsely increased profit of 40.231 million yuan. In April 2013, Wanfu Shengke disclosed a cumulative false increase of 740 million yuan from 2008 to 2011, and falsely increased operating profit 180 million yuan, a virtual increase in net profit of 160 million yuan. Anyone who bought the company's stock during this vacation can file a civil lawsuit to claim compensation. The company's normal stock price that should have risen is believed to have caused the stock price to fall and affect the stock. The normal development of the market.

\subsection{Lack of reasonable market mechanism}

For the current stock market, the development time is not long, so the market mechanism is not very perfect. Therefore, the imperfect market mechanism will also restrict the operation and development of the stock market.

There is a serious lack of short selling mechanism. According to Ye Binwen's introduction, the short selling mechanism in China's stock market faces three major problems. The first point is that the funds for short selling business are too low in efficiency, mainly because the margin ratio is too high and the transaction threshold is too high. The problem makes the final absolute return low. The second point of short selling is difficult to be discerned because many short selling behaviors such as borrowing are done in private, and it is difficult for regulators to grasp absolute evidence to prove this short selling behavior. The third point of selling Because of legal reasons, short-selling operators can influence the stock price by manipulating the associated stock price to carry out short selling. This way, the law is also difficult to convict.

China's delisting mechanism is currently not perfect. There are still many places to make repairs, but what is more serious is that the operation efficiency of the delisting mechanism in China's stock market is worrying. This has led to the phenomenon that China's stock market has stopped and did not retreat for a while. Formulating and perfecting the delisting mechanism, currently increasing execution is the most critical step.

\section{Conclusion}

China's stock market has been disconnected from the macro economy for a long time, and has a close relationship with monetary policy, and the proportion of state-owned shares is too large. As a result, there is no linear correlation between the excess return of the stock market and the excess return of individual stocks, and CAPM cannot effectively explain the Individual stock return problem.

Based on the above conclusions, the author made the following suggestions. 


\section{Suggestions for improving the effectiveness of the Chinese stock market}

\subsection{Reduce macro-control}

According to current policies, in 2018, Premier Li Keqiang proposed "Minimizing the direct intervention of the government in market activities". However, there are still many departments that have not decentralized their powers, and should release their powers, especially the powers of market permits, etc. Only in this way can the investment of enterprises and the entrepreneurial innovation of the masses be actively followed, and the direct allocation of market resources by the government can be avoided as much as possible, so that the advantages of the market economy can be brought into play, and the allocation of resources can be more reasonable.

\subsection{Supervision of listed companies with information disclosure as the core}

At present, we should increase the punishment for illegal acts in the stock market, which can play a deterrent role, so as to ensure the natural and orderly development of the stock market. Compared with the US self-regulatory organization, it is composed of the Securities Industry Association and the Securities Dealers Association. Clearly, the problem of offside and duplication of supervision is eliminated. The self-regulatory organizations in China should also cooperate with each other to carry out a clear division of labor so that they can play the supervisory role of the self-regulatory organizations. In order to protect the rights and interests of investors, companies that falsify information should be severely punished, and pay attention to company transactions, reorganization and other behaviors to avoid damage to investors' rights and interests in a timely manner.

\section{Reference}

1. Yunhui, Liu Lin. An empirical study of CAPM in the Chinese market [J]. Financial Research, 2001 (7): 106-115.

2. Xie Baohua, Ma Zheng, Gao Rongxing. Empirical Test of the Effectiveness of China's Stock Market [J]. Journal of Guangdong University of Commerce, 2001 (5): $22-25$.

3. Hu Changsheng, Liu Hong. An empirical study on the effectiveness of China's stock market [J]. Statistics and Decision, 2004 (11): 45-46.

4. Gu Rongbao, Liu Haifei, Li Xindan, Li Long. Herd behavior and volatility in the stock market: Correlation and its evolution (1)_Evidence from Shenzhen stock market -94 .

5. Li Linxiang. Effectiveness Test and Return Fluctuation Characteristics of China's Stock Market_Data Analysis Based on Shanghai Stock
Index [J]. Market Economy and Price, 2014 (11): 4348.

6. Luo, Y. Misvaluation comovement, market efficiency and the cross-section of stock returns: Evidence from China [J]. Economic Systems, 2015 (39): 390-412.

7. Wang Weihan. An empirical study on the effectiveness of the CAPM model in the Chinese stock market [J]. Yinshan Journal (Natural Science Edition), 2017 (31): 101-103.

8. Qu Hui. A New Test of the Effectiveness of Chinese Stock Market Based on Genetic Programming. Statistics and Decision, 2011 (23): 137-142.

9. Wang Hongxia, Cao Bo.. Validation of Chinese stock market based on genetic programming [J]. Computer Science, 2016 (S1): 538-541.

10. Wei Sun. China's A-Share, B-Share, and H-Share Stock Markets and the World Financial Markets: A Cointegration and Causality Analysis [J].Journal of Applied Business and Economics, 2014 (16: 70-80.

11. Tan Xueyan. Analysis of the Effectiveness of China's Stock Market Based on Institutional Changes [J]. Journal of Central University of Finance and Economics, 2010 (9): 44-47.

12. Ran Maosheng, Zhang Zongyi, Chen Rong. Using the $\mathrm{R} / \mathrm{S}$ method to study the effectiveness of China's stock market [J]. Journal of Chongqing University: Natural Science Edition, 2001,24 (6): 92-95.

13. Li Jia, Wang Xiao. An empirical study on the effectiveness of China's stock market—Test method based on variance ratio [J]. Economic Survey, 2010 (1): 137-140.

14. Deng Zilai, Hu Jian. Market efficiency theory and empirical test of the effectiveness of China's stock market [J]. Financial Forum, 2001 (10): 44-50.

15. Ma Yanxiang. An Empirical Analysis of the Effectiveness of China's Stock Market [J]. Xinjiang Finance and Economics, 2009 (5): 47-50.

16. Zhu Konglai, Li Jingjing. The compound evaluation of the effectiveness of China's stock market [J]. Mathematical Statistics and Management, 2013,32 (1): 145-154.

17. Zeng Jinsong. Technical Analysis and Effectiveness of China's Stock Market [J]. Research on Financial Problems, 2005 (8): 27-30.

18. Zhao Shengmin, Yan Honglei, Zhang Kai. Is the Fama-French five-factor model better than the threefactor model-empirical evidence from China's Ashare market [J]. Nankai Economic Research, 2016 (2): 41-59.

19. Shi Qiang, Yang Yiwen, Liu Yakai. The relationship between macroeconomics and stock market volatility based on GARCH-MIDAS model [J]. Computer Engineering and Applications, 2019,55 (15): 257-262 +270 .

20. Wu Kaijun. The disadvantages of excessively large proportion of state-owned shares and their countermeasures [J]. Journal of Huaiyin Polytechnic College, 1998 (Z1): 123-125. 
21. Liu Tingna. Research on the Improper Use of Overraised Funds of Listed Companies on GEM [D]. Jiangxi Normal University, 2019.

22. Ye Bin. Analysis of the short mechanism of China's stock market [J]. Shang, 2016 (20): 189.

23. Wang Hui. Defects of China's stock delisting system and improvement measures [J]. Knowledge Economy, 2015 (02): $96+98$. 